\title{
Curing reaction of bisphenol-A based benzoxazine with cyanate ester resin and the properties of the cured thermosetting resin
}

\author{
H. Kimura*, K. Ohtsuka, A. Matsumoto \\ Thermosetting Resin Lab., Organic Materials Research Division, Osaka Municipal Technical Research Institute, 1-6-50, \\ Morinomiya, Joto-ku, Osaka, 536-8553 Japan
}

Received 9 May 2011; accepted in revised form 4 July 2011

\begin{abstract}
Curing reaction of bisphenol-A based benzoxazine with cyanate ester resin and the properties of the cured thermosetting resin were investigated. The cure behavior of benzoxazine with cyanate ester resin was monitored by model reaction using nuclear magnetic resonance (NMR). As a result of the model reaction, the ring opening reaction of benzoxazine ring and thermal self-cyclotrimerization of cyanate ester group occurred, and then the phenolic hydoroxyl group generated by the ring opening reaction of benzoxazine ring co-reacted with cyanate ester group. The properties of the cured thermosetting resin were estimated by mechanical properties, electrical resistivity, water resistance and heat resistance. The cured thermosetting resin from benzoxazine and cyanate ester resin showed good heat resistance, high electrical resistivity and high water resistance, compared with the cured thermosetting resin from benzoxazine and epoxy resin.
\end{abstract}

Keywords: thermosetting resins, benzoxazine, cyanate ester resin

\section{Introduction}

Phenolic resin is used widely as an industrial material because of its good heat resistance, electrical insulation, dimensional stability, and chemical resistance. However, there are a number of shortcomings associated with those traditional phenolic resins. For example, hexamethylenetetramine (hexamine) is used as a curing agent. In the curing process of novolac-hexamine, volatiles such as water or ammonia compounds etc. are released due to the condensation reaction. These volatiles sometimes reduce the properties of cured phenolic resin because of the formation of microvoids. Moreover acid or base compounds as catalysts must be used to synthesize novolac or resole precursors of cured phenolic resin, which result in corrosion of the processing equipment. Another problem is that the cured phenolic resin is brittle.
It is well known that the benzoxazine ring is stable at low temperature, but a ring opening reaction occurs at high temperature, and novolac type oligomers having both phenolic hydroxyl group and tertiary amine group are produced [1]. Using this benzoxazine compound as a phenolic resin, it is expected to develop a new type of phenolic resin that releases no volatiles during curing reaction and needs no catalysts.

Ishida and co-workers [2-24] synthesized a lot of types of oxazines and studied their cure kinetics, molecular structures, mechanical and dynamic mechanical properties, and so on. Jang and Shin also studied the cure kinetics of a benzoxazinebased phenolic resin [25]. Jang and Seo studied the performance improvement of rubber-modified polybenzoxazine [26]. Recently, maleimide-modified [22-23, 27-28] and furan-modified [29] benzox-

\footnotetext{
${ }^{*}$ Corresponding author, e-mail: kimura@omtri.or.jp
}

(c) BME-PT 
azines have been synthesized, and the properties of the cured resins have been investigated. Nanocomposites using benzoxazines also recently have been reported [30-33].

We also have already investigated the curing behavior of the bisphenol-A, terpenediphenol or $\operatorname{poly}(p-$ vinylphenol) based benzoxazines with epoxy resin or bisoxazoline and the properties of the cured resins [34-41]. Consequently, the molding compound from bisphenol-A based benzoxazine and epoxy resin or bisoxazoline showed good flowability below $140^{\circ} \mathrm{C}$, curing reaction proceeded above $180^{\circ} \mathrm{C}$ rapidly. And the cured thermosetting resins from benzoxazine compounds and epoxy resin or bisoxazoline had superior heat resistance, electrical resistivity, mechanical properties and water resistance to the cured thermosetting resins from conventional bisphenol-A type novolac and epoxy resin or bisoxazoline.

In this report, we investigated the curing behavior of benzoxazine resin with cyanate ester resin and the properties of the cured thermosetting resin.

Cyanate ester resin has drawn a great deal of attention as one of the high-performance thermosets, comparable to epoxy resins and polyimide. The cyanate ester monomer undergoes thermal selfcyclotrimerization to form a three-dimensional net- work structure of polycyanurate containing triazine groups $[42,43]$. Polycyanurate possesses several superior properties including high heat resistance, low moisture absorption, high electrical resistivity, low dielectric constant, and low shrinkage. Therefore it is also expected that the cured thermosetting resin from benzoxazine resin and cyanate ester resin has high heat resistance, high electrical resistivity and low moisture absorption. 2,2-bis(4cyanatophenyl) propane (bisphenol-A based cyanate ester resin) is a widely accepted cyanate ester monomer used in wide range applications. In this study, we investigated the curing behavior of bisphenol-A based benzoxazine with bisphenol-A based cyanate ester resin and the properties of the cured thermosetting resin.

\section{Experimental}

2.1. Materials

2,2-bis(3,4-dihydro-3-phenyl-1,3-benzoxazine) propane (bisphenol-A based benzoxazine, Ba) and 2-(3,4-dihydro-3-phenyl-1,3-benzoxazine) butane (mono functional benzoxazine, $\mathrm{BuPa}$ ) was supplied by Shikoku Chemicals Co., Ltd. (Kagawa, Japan). 2,2-bis(4-cyanatophenyl) propane (bisphenol-A based cyanate ester, BADCy) and 2-phenyl-2-(4cyanatophenyl) propane (mono functional cyanate

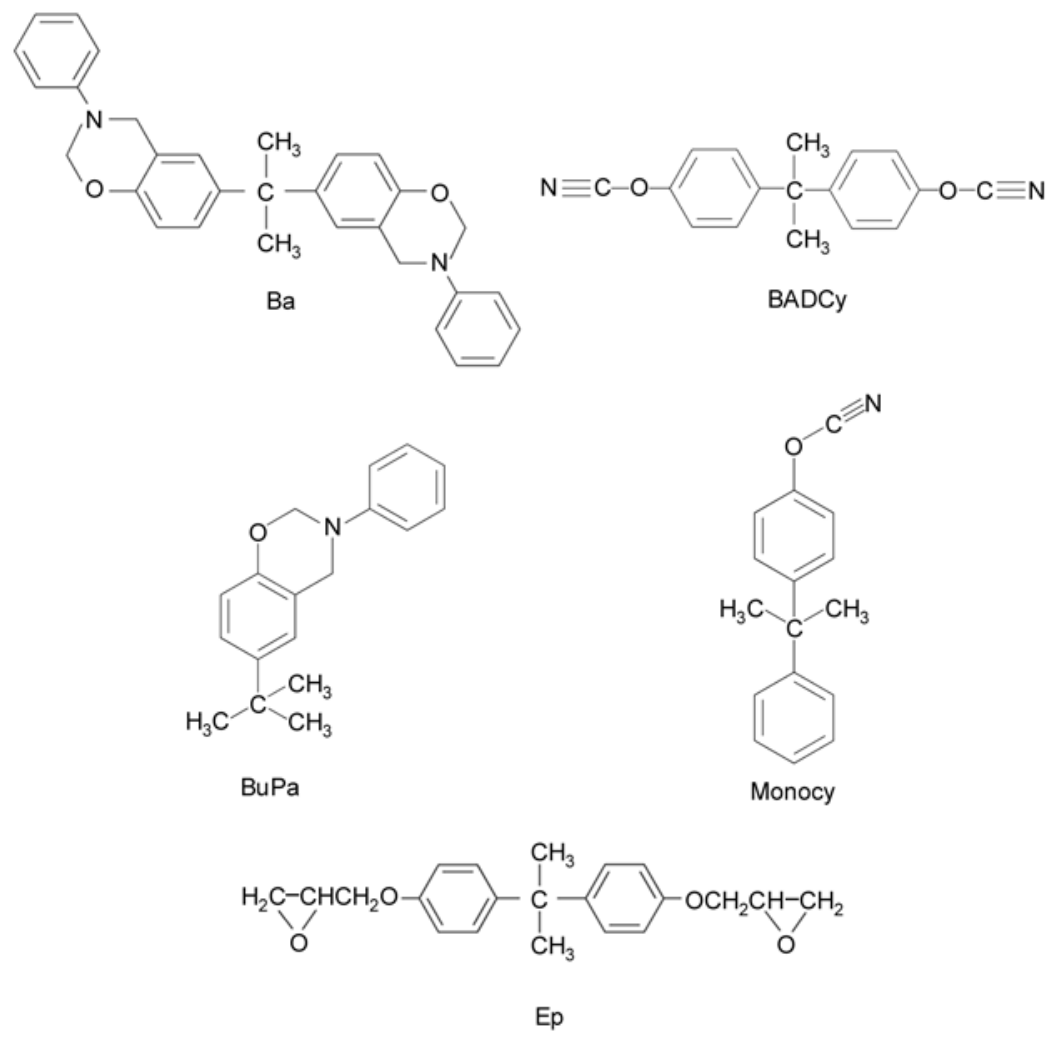

Figure 1. Chemical structures of $\mathrm{Ba}, \mathrm{BuPa}, \mathrm{BADCy}$, Monocy and $\mathrm{Ep}$ 
ester, Monocy) was supplied by Mitsubishi Gas Chemical Company, Inc. (Tokyo, Japan). Bisphenol A based epoxy resin (EPIKOTE 828, epoxy equivalent 186) as an epoxy resin (Ep) was supplied by Japan Epoxy Resins Co., Ltd. (Tokyo, Japan). All chemicals were used without further purification. The chemical structures of $\mathrm{Ba}, \mathrm{BuPa}, \mathrm{BADCy}$, Monocy and Ep are shown in Figure 1.

\subsection{Model reaction and characterization}

It is difficult to investigate the curing reaction of $\mathrm{Ba}$ with BADCy in detail because both Ba and BADCy have two functionalities and gelation occurs easily, and so the compound from the reaction is partially insoluble in solvents used for the measurement of nuclear magnetic resonance (NMR) such as $\mathrm{CDCl}_{3}$, acetone-D, $\mathrm{CD}_{3} \mathrm{OD}$ and so on. In this way, $\mathrm{BuPa}$ and Monocy were used as each model compounds in order to investigate curing behavior of benzoxazine (Ba) with cyanate ester resin (BADCy), because both $\mathrm{BuPa}$ and Monocy have mono functionality and gelation does not occur, and it is easy to investigate the curing reaction. The structures of the compounds obtained by model reaction (reaction of $\mathrm{BuPa}$ with Monocy) were analyzed by ${ }^{13} \mathrm{C}$-NMR measurement. ${ }^{13} \mathrm{C}$-NMR measurement was carried out on Japan Electron Company (Tokyo, Japan) JMN-GSX-270 instrument operating at $67.8 \mathrm{MHz}$. Deuterated chloroform was used as a solvent and tetramethylsilane was used as an internal standard.

\subsection{Curing condition}

Samples containing $50 \mathrm{~mol} \% \mathrm{Ba}$ and $50 \mathrm{~mol} \%$ BADCy were prepared and cured in a mold at a specified temperature in the oven. The curing condition of $\mathrm{Ba}$ with $\mathrm{BADCy}$ was determined as $180^{\circ} \mathrm{C} / 2 \mathrm{~h}+200^{\circ} \mathrm{C} / 2 \mathrm{~h}+220^{\circ} \mathrm{C} / 2 \mathrm{~h}$ from the results of Fourier Transform Infrared Spectrophotometer (FT-IR). For comparison, the curing reaction of $50 \mathrm{~mol} \%$ Ba with $50 \mathrm{~mol} \%$ Ep was also carried out. The curing condition of $\mathrm{Ba}$ with Ep was determined as $170^{\circ} \mathrm{C} / 2 \mathrm{~h}+190^{\circ} \mathrm{C} / 2 \mathrm{~h}+200^{\circ} \mathrm{C} / 2 \mathrm{~h}+220^{\circ} \mathrm{C} / 2 \mathrm{~h}$ from the results of previous paper [34].

\subsection{Properties of the molding compound and the cured resin}

The structure of the cured thermosetting resin was analyzed by Fourier Transform Infrared Spectrophotometer (FT-IR). FT-IR measurement was carried out on Nicolet Impact 420 instrument (Thermo Fisher Scientific K.K, Yokohama, Japan). The spectral range was $4000-400 \mathrm{~cm}^{-1}$. One hundred twentyeight scans were coadded at a resolution of $4 \mathrm{~cm}^{-1}$. Samples were prepared as $\mathrm{KBr}$ pellets.

Differential scanning calorimetry (DSC) was applied to evaluate the cure behavior. DSC was measured with heating rate of $10^{\circ} \mathrm{C} / \mathrm{min}$ under $\mathrm{N}_{2}$ atmosphere on a Seiko Instruments Co., Ltd., (Chiba, Japan) STI EXSTAR 6000.

Thermal gravimetric analysis (TGA) was applied to evaluate the thermal stability. TGA was measured with heating rate of $10^{\circ} \mathrm{C} / \mathrm{min}$ under $\mathrm{N}_{2}$ atmosphere on a Seiko Instruments Co., Ltd. (Chiba, Japan) TGA 5200 Thermal Gravimetric Analyzer.

In order to investigate the thermal stability of the molding compound, gelation time was estimated according to JIS K6910. Namely, spatula was placed on the steel plate and the steel plate and spatula was heated to the constant temperature. Approximately $0.5 \mathrm{~g}$ of the sample was put on the steel plate and spread to a disc approximately $3 \mathrm{~cm}$ in diameter with the spatula. Then the sample was kneaded by pressing it uniformly approximately once a second, but with care to avoid spreading. The time until when the sample does not string to the spatula any more was measured. It was taken as the gelation time of the sample.

The properties of the cured thermosetting resin were characterized by heat resistance, fracture toughness, electrical insulation and water absorption.

Heat resistance was estimated by glass transition temperature $\left(T_{\mathrm{g}}\right)$ on dynamic mechanical analysis. Dynamic mechanical analysis was measured by a three points bending method at $1 \mathrm{~Hz}$, with a heating rate of $2{ }^{\circ} \mathrm{C} / \mathrm{min}$ on a Seiko Instruments Co., Ltd (Chiba, Japan) DMS-110 Dynamic Mechanical Analysis Spectrometer. The peak temperature of $\tan \delta$ by dynamic mechanical analysis was considered as $T_{\mathrm{g}}$ [44].

Fracture toughness was estimated by critical stress intensity factor $\left(K_{\mathrm{IC}}\right)$ according to ASTM D5045.

Electrical insulation was estimated by volume resistivity. Volume resistivity was measured by Yokogawa-Hewlett-Packard Co., Ltd (Tokyo, Japan) HP4339A according to JIS K6911. Namely, the disk test pieces (approximately $50 \mathrm{~mm}$ diameter and $3 \mathrm{~mm}$ thickness) were charged with electricity $(500 \mathrm{~V})$, and after $1 \mathrm{~min}$ volume resistance was 
measured. Volume resistivity was calculated by the Equation (1):

$$
\rho_{\mathrm{V}}=\frac{\pi d^{2}}{4 t} \cdot R_{\mathrm{V}}
$$

where $\rho_{\mathrm{V}}$ is the volume resistivity; $d$ is the outside diameter of inner circle of face electrode, $t$ is the thickness of test piece, and $R_{\mathrm{V}}$ is the volume resistance.

Water absorption was estimated according to JIS K7209. Namely, the disk test pieces (approximately $50 \mathrm{~mm}$ diameter and $3 \mathrm{~mm}$ thickness) were weighed to the nearest $0.1 \mathrm{mg}$, and the mass was taken as $M_{1}$. Then the test pieces were put in a container containing boiling water. After $2 \mathrm{~h}$, the test pieces were taken out of the boiling water and cooled down by putting them in water kept at the temperature of the testing room for $15 \mathrm{~min}$. After taking the test pieces out of the water, they were weighed to the nearest $0.1 \mathrm{mg}$, and the mass was taken as $M_{2}$. Water absorption was calculated by the Equation (2):

$$
\text { Water absorption }[\%]=\frac{M_{2}-M_{1}}{M_{1}} \cdot 100
$$

\section{Results and discussion}

\subsection{Model reaction}

${ }^{13} \mathrm{C}$-NMR spectrum of the product obtained by model reaction (reaction of BuPa with Monocy) at $200^{\circ} \mathrm{C}$ for $1 \mathrm{hr}$ is shown in Figure 2. As a result, both<smiles>CC(C)(c1ccccc1)c1ccc(OC#N)cc1</smiles>

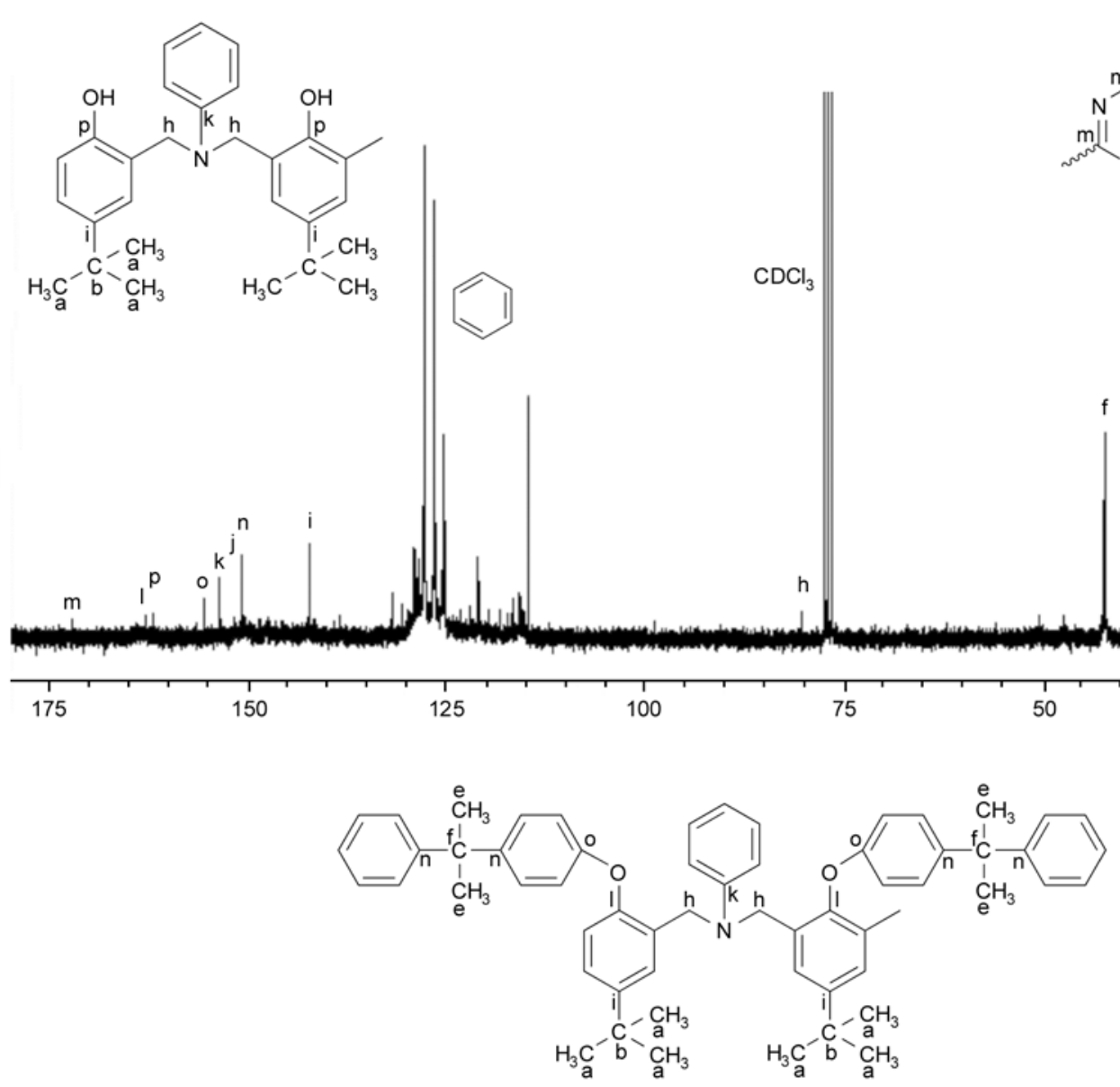

Figure $2 .{ }^{13} \mathrm{C}-\mathrm{NMR}$ spectrum of the product obtained by model reaction at $200^{\circ} \mathrm{C}$ for $1 \mathrm{hr}$
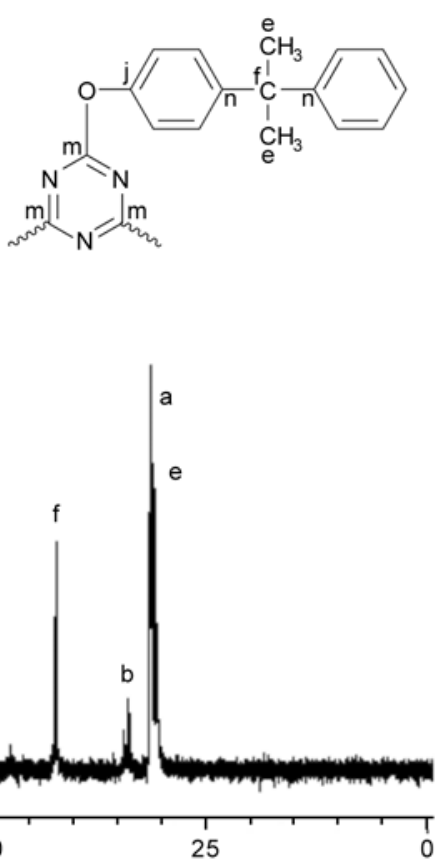
two peaks (x, $79.1 \mathrm{ppm}$ and y, $50.7 \mathrm{ppm})$ assigned to the carbon of benzoxazine ring and a peak $(\mathrm{z}$, $108.8 \mathrm{ppm}$ ) assigned to the carbon of cyanate ester group were not detected. The peak (p) assigned to $\mathrm{C} 1$ carbon of the benzene ring adjacent to phenolic hydroxyl group generated by the ring opening reaction of benzoxazine ring was detected. The peak $(\mathrm{h})$ assigned to methylene carbon of

$\mathrm{Ph}(\mathrm{OH})-\mathrm{CH}_{2}-\mathrm{N}(\mathrm{Ph})-\mathrm{CH}_{2}-\mathrm{Ph}(\mathrm{OH})$,

which was produced by the ring-opening reaction of benzoxazine ring, was also detected. It was found that the ring-opening reaction of the benzoxazine ring occurred (Figure 3). And the peak (m) assigned to $\mathrm{C} 1$ carbon of the benzene ring adjacent to triazine group generated by the thermal selfcyclotrimerization of cyanate ester group was detected. It was found that thermal self-cyclotrimerization of cyanate ester group occurred (Figure 3). Furthermore, the peak (1) assigned to $\mathrm{C} 1$ carbon of the benzene ring adjacent to ether bond was detected. It was suggested that the phenolic hydroxyl group produced by the ring opening reaction of $\mathrm{BuPa}$ reacted with cyanate ester group of Monocy. Namely, shown in Figure 4, the phenolic hydroxyl group produced by the ring opening reaction of benzoxazine co-reacted with cyanate ester group to form the intermediate iminocarbonate, which further induce curing reaction of cyanate ester to form polycyanulate.

\subsection{Curing reaction of $\mathrm{Ba}$ with $\mathrm{BADCy}$}

To investigate the curing reaction of Ba with BADCy, FT-IR measurement was carried out. FT-IR spectra of the compound before and after the curing reaction of Ba with BADCy are shown in Figure 5. As a result, the absorption at $949 \mathrm{~cm}^{-1}$ assigned to the tri-substituted benzene ring in the benzoxazine ring structure disappeared after $2 \mathrm{~h}$ at $180^{\circ} \mathrm{C}$ (Figure 5b). And the absorptions at 2266 and $2230 \mathrm{~cm}^{-1}$ assigned to cyanate ester group also disappeared after $2 \mathrm{~h}$ at $180^{\circ} \mathrm{C}$ (Figure 5b). The new absorptions at 1565 and $1370 \mathrm{~cm}^{-1}$ assigned to the triazine group appeared after $2 \mathrm{~h}$ at $220^{\circ} \mathrm{C}$ (Figure $5 \mathrm{~d}$ ). It was found the ring opening reaction of benzoxazine ring and thermal self-cyclotrimerization of cyanate ester group occurred, and then the phenolic hydroxyl groups generated by the ring-opening reaction of benzoxazine ring might react with cyanate ester as shown in Figure 4 from the results of model reaction.

From the results of FT-IR measurement, the curing condition was determined as follows: after the molding compound softened at $150^{\circ} \mathrm{C}$ to remove any bubbles containing in it sufficiently, curing reaction was carried out stepwise at $180^{\circ} \mathrm{C} / 2 \mathrm{hr}+$ $200^{\circ} \mathrm{C} / 2 \mathrm{hr}$. Finally, at $220^{\circ} \mathrm{C} / 2 \mathrm{hr}$ the cured thermosetting resin was postcured so that the curing reaction could proceed completely. In this way, the curing condition of $\mathrm{Ba}$ with $\mathrm{BADCy}$ was determined as $180^{\circ} \mathrm{C} / 2 \mathrm{hr}+200^{\circ} \mathrm{C} / 2 \mathrm{hr}+220^{\circ} \mathrm{C} / 2 \mathrm{hr}$.<smiles>Cc1cc(C(C)(C)C)cc(CN(Cc2cc(C(C)(C)C)cc(CN(Cc3cc(C(C)(C)C)cc(CN(c4ccccc4)c4ccc(C(C)(C)C)cc4CN(Cc4ccccc4)c4ccc(C(C)(C)C)cc4O)c3O)c3ccccc3)c2O)c2ccccc2)c1O</smiles>

BuPa
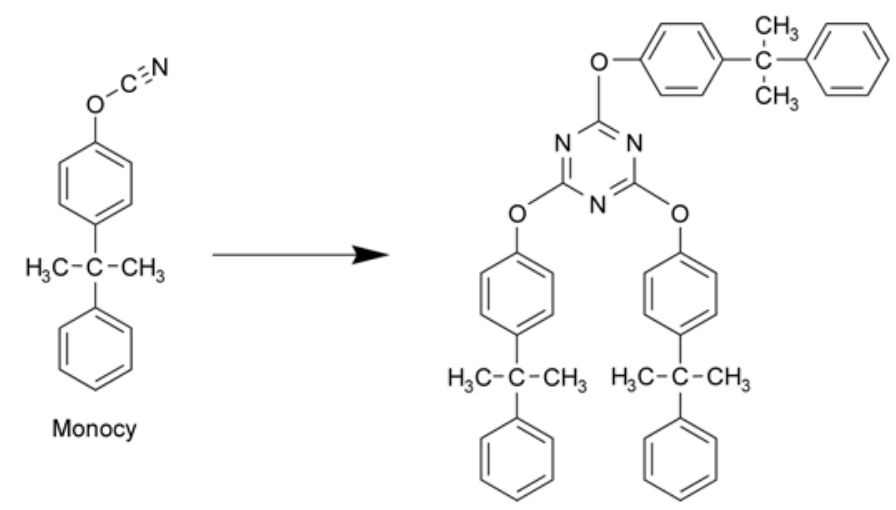

Figure 3. Ring-opening reaction of benzoxazine $(\mathrm{BuPa})$ and thermal self-cyclotrimerization of cyanate ester (Monocy) 


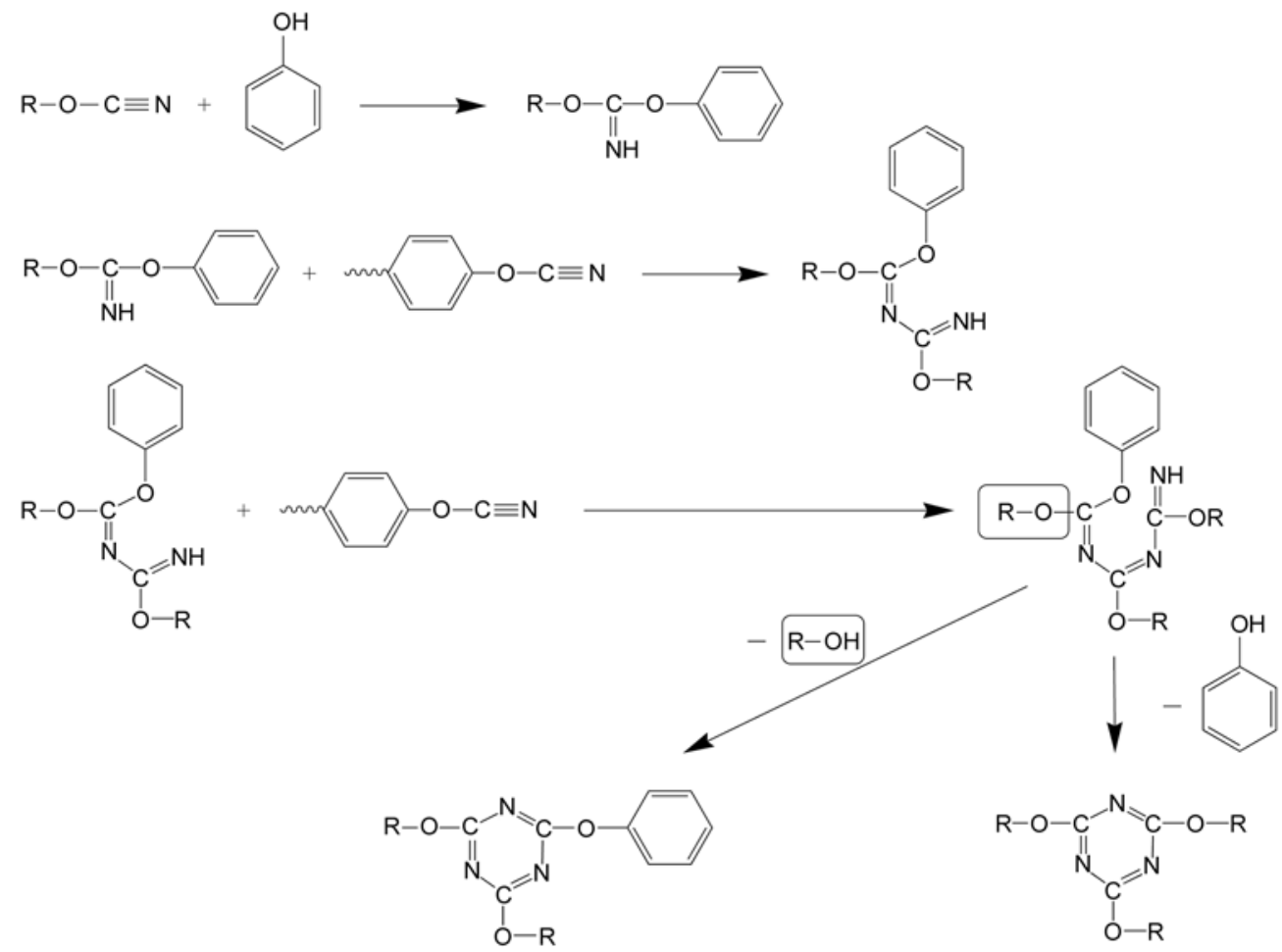

Figure 4. Co-reaction of benzoxazine (BuPa) with cyanate ester (Monocy)

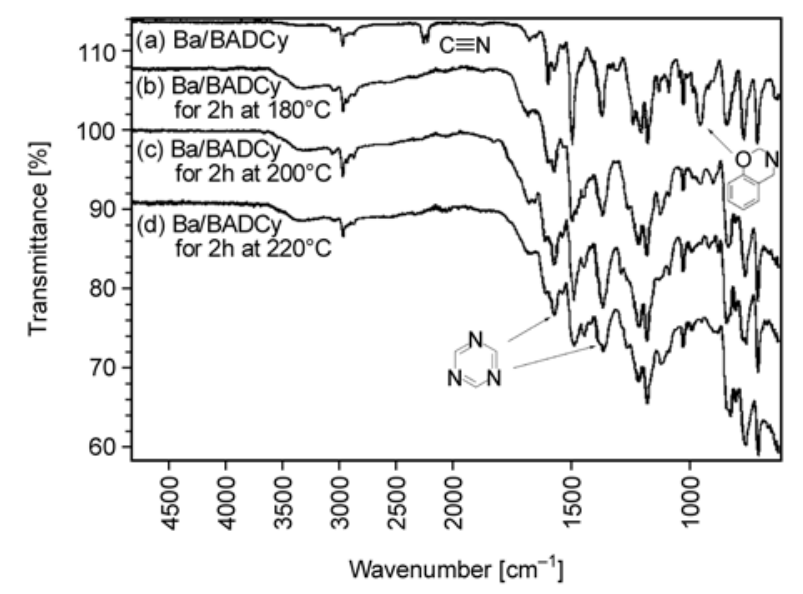

Figure 5. FT-IR spectra of the compound from curing reaction of $50 \mathrm{~mol} \% \mathrm{Ba}$ with $50 \mathrm{~mol} \% \mathrm{BADCy}$. (a) before curing reaction, (b )after $180^{\circ} \mathrm{C} / 2 \mathrm{hr}$, (c) after $180^{\circ} \mathrm{C} / 2 \mathrm{hr}+200^{\circ} \mathrm{C} / 2 \mathrm{hr}$, (d) after $180^{\circ} \mathrm{C} / 2 \mathrm{hr}+200^{\circ} \mathrm{C} / 2 \mathrm{hr}+220^{\circ} \mathrm{C} / 2 \mathrm{hr}$.

\subsection{Thermal stability of the molding compound from Ba and BADCy}

The gelation time of the molding compounds from $50 \mathrm{~mol} \% \mathrm{Ba}$ and $50 \mathrm{~mol} \%$ BADCy was measured. Furthermore, the reciprocal plot of gelation time as a function of temperature is shown in Figure 6. The molding compound was thermally stable under $120^{\circ} \mathrm{C}$ for about $45 \mathrm{~min}$, because the curing reaction could not occur. This was because the ring opening reaction of benzoxazine ring was difficult to occur

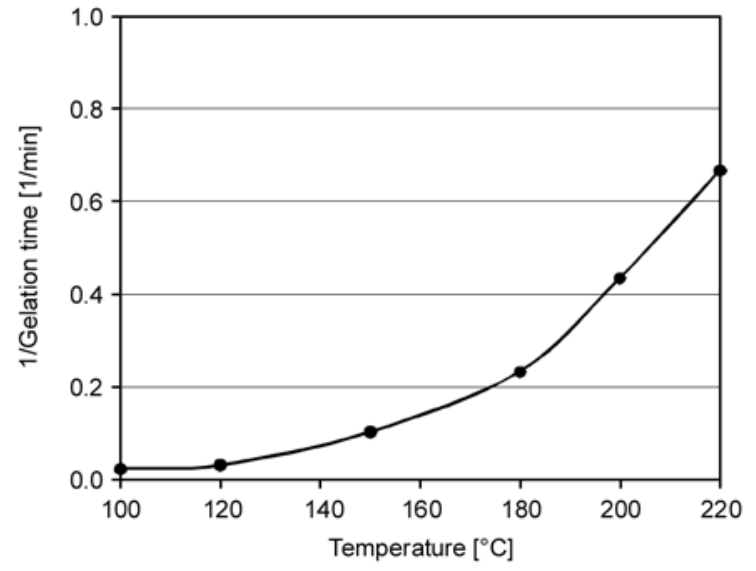

Figure 6. Reciprocal plot of gelation time as a function of temperature

under $120^{\circ} \mathrm{C}$, especially under dilution by BADCy, and the phenolic hydroxyl groups that contributed to the curing reaction were not produced. However, the gelation time was shortened with the rise of the molding temperature, because the benzoxazine ring opened and the phenolic hydroxyl groups that contributed to the curing reaction were produced easily, and thermal self-cyclotrimerization of cyanate ester group occurred.

\subsection{DSC analysis of the molding compound}

Figure 7 shows the DSC curves of the molding compounds from $\mathrm{Ba}$ and BADCy or Ep. From the 


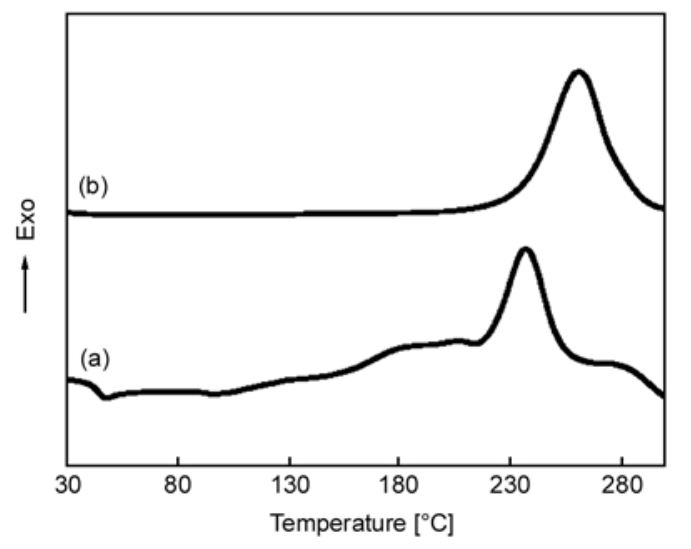

Figure 7. DSC curves of the molding compounds from $\mathrm{Ba}$ and BADCy or Ep. (a) Ba + BADCy, (b) Ba + Ep.

results of DSC, the maximum exotherm temperature (peak temperature) of the molding compounds from $\mathrm{Ba}$ and BADCy shifted to lower temperature side by about $20^{\circ} \mathrm{C}$, compared with that of the molding compounds from $\mathrm{Ba}$ and Ep. It was found that the curing reaction of Ba with BADCy could proceed more rapidly than that of $\mathrm{Ba}$ with Ep. The reason might be considered that the co-reaction of the phenolic hydroxyl group produced by the ring opening reaction of benzoxazine with cyanate ester group occurred more rapidly than that of the phenolic hydroxyl group produced by the ring opening reaction of benzoxazine with epoxy group.

\subsection{TGA analysis of the molding compound}

Figure 8 shows the TGA curves of the molding compounds from $\mathrm{Ba}$ and $\mathrm{BADCy}$ or Ep. For the molding compounds from $\mathrm{Ba}$ and $\mathrm{BADCy}$, the initial decomposition that was defined as $5 \mathrm{wt} \%$ of mass loss occurred about $330^{\circ} \mathrm{C}$ and the char yield at $600^{\circ} \mathrm{C}$ was $44 \mathrm{wt} \%$. For the molding compounds from $\mathrm{Ba}$ and $\mathrm{Ep}$, the initial decomposition that was defined as $5 \mathrm{wt} \%$ of mass loss occurred about $310^{\circ} \mathrm{C}$ and the char yield at $600^{\circ} \mathrm{C}$ was $27 \mathrm{wt} \%$. In terms of the thermal gravimetric results, the thermal decomposition stability of the molding compounds from $\mathrm{Ba}$ and $\mathrm{BADCy}$ was superior to that of the molding compounds from $\mathrm{Ba}$ and $\mathrm{Ep}$.

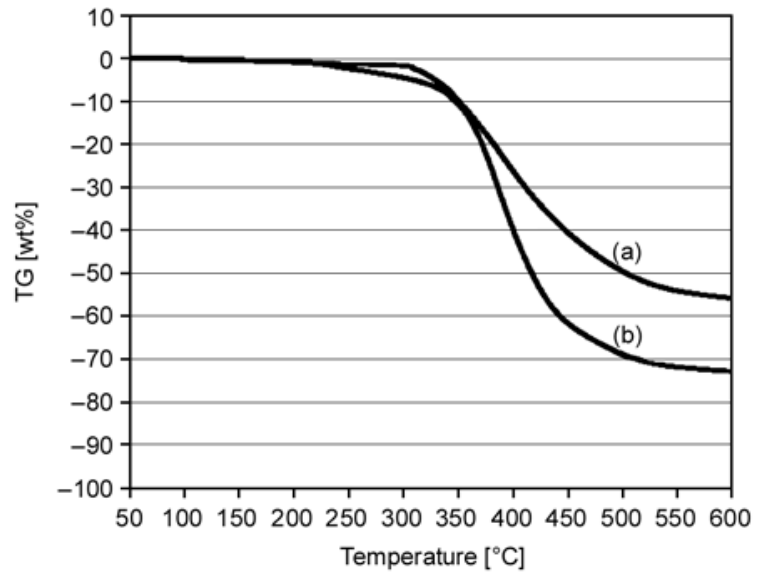

Figure 8. TGA curves of the molding compounds from $\mathrm{Ba}$ and BADCy or Ep. (a) Ba + BADCy, (b) Ba + Ep.

\subsection{Properties of the cured thermosetting resin}

The properties of the cured thermosetting resins from $\mathrm{Ba}$ and BADCy or Ep are shown in Table 1. And the curves of Dynamic mechanical analysis (DMA) are shown in Figure 9. As a result, glass transition temperature $\left(T_{\mathrm{g}}\right)$ of the cured thermosetting resin from $\mathrm{Ba}$ and BADCy was much higher than that of the cured thermosetting resins from $\mathrm{Ba}$ and Ep. The cured thermosetting resin from $\mathrm{Ba}$ and BADCy had extremely high volume resistivity of commercial resins, and volume resistivity of the cured thermosetting resin from $\mathrm{Ba}$ and $\mathrm{BADCy}$ was a little higher than that of the cured thermosetting

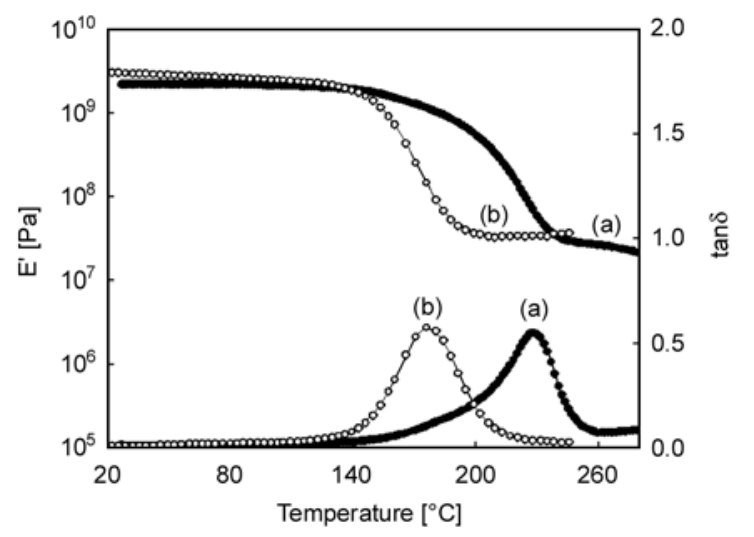

Figure 9. DMA curves of the cured thermosetting resins from $\mathrm{Ba}$ and BADCy or Ep. (a) Ba/BADCy, (b) $\mathrm{Ba} / \mathrm{Ep}$.

Table 1. Properties of the cured thermosetting resins

\begin{tabular}{|c|c|c|c|c|c|}
\hline \multirow{2}{*}{ Sample } & \multirow{2}{*}{$\begin{array}{l}\mathbf{T}_{\mathbf{g}}{ }^{\mathbf{a}} \\
{\left[{ }^{\circ} \mathbf{C}\right]}\end{array}$} & \multirow{2}{*}{$\begin{array}{c}\mathbf{K}_{\mathrm{IC}} \\
{\left[\mathrm{MPa} \cdot \mathbf{m}^{1 / 2}\right]}\end{array}$} & \multicolumn{2}{|c|}{ Volume resistivity $[\Omega \cdot c m]$} & \multirow{2}{*}{$\begin{array}{c}\text { Water absorption }^{b} \\
{[w t \%]}\end{array}$} \\
\hline & & & Before boiling & After $2 \mathrm{~h}$ boiling & \\
\hline $\mathrm{Ba} / \mathrm{BADCy}$ & 223 & 0.61 & $5.5 \cdot 10^{16}$ & $5.2 \cdot 10^{15}$ & 0.26 \\
\hline $\mathrm{Ba} / \mathrm{Ep}$ & 175 & 0.54 & $4.0 \cdot 10^{16}$ & $1.2 \cdot 10^{15}$ & 0.46 \\
\hline
\end{tabular}

aPeak temperature of $\tan \delta$ by DMA.

${ }^{\mathrm{b}}$ After $2 \mathrm{~h}$ boiling. 
resins from $\mathrm{Ba}$ and Ep. $K_{\mathrm{IC}}$ of the cured thermosetting resin from $\mathrm{Ba}$ and BADCy was also slightly higher than that of the cured thermosetting resin from $\mathrm{Ba}$ and $\mathrm{Ep}$. Water absorption after $2 \mathrm{~h}$ boiling of the cured thermosetting resin from $\mathrm{Ba}$ and BADCy was superior to that of the cured thermosetting resin from $\mathrm{Ba}$ and $\mathrm{Ep}$. The reason of these results (good heat resistance, high electrical resistivity and high water resistance) might be due to the formation of rigid and hydrophobic triazine ring by thermal self-cyclotrimerization of cyanate ester group [43].

\section{Conclusions}

In this study, we investigated the curing reaction of bisphenol-A based benzoxazine with cyanate ester resin and the properties of the cured thermosetting resin. As a result of model reaction, it was found that the ring opening reaction of benzoxazine ring and thermal self-cyclotrimerization of cyanate ester group occurred. Furthermore, it was suggested that the phenolic hydroxyl group produced by the ring opening reaction of benzoxazine co-reacted with cyanate ester group to form the intermediate imonocarbonate, which further induce curing reaction of cyanate ester to form polycyanulate containing triazine groups. The molding compound from benzoxazine and cyanate ester resin showed good thermal stability below $120^{\circ} \mathrm{C}$, but above $160^{\circ} \mathrm{C}$ the curing reaction of benzoxazine with cyanate ester resin proceeded more rapidly. From the thermal gravimetric results, the thermal decomposition stability of the molding compounds from benzoxazine and cyanate ester resin was superior to that of the molding compounds from benzoxazine and epoxy resin. The cured thermosetting resin from benzoxazine and cyanate ester resin had superior heat resistance, electrical resistance and water resistance to those from benzoxazine and epoxy resin. This might be because rigid and hydrophobic triazine ring structure was incorporated into the backbone of the cured thermosetting resin by thermal self-cyclotrimerization of cyanate ester group.

\section{References}

[1] Riess G., Schwob J. M., Guth G., Roche M., Lande B.: Ring opening polymerization of benzoxazines. in 'Advances in polymer synthesis' (eds.: Culbertson B. M., Mcgrath J. E.) 27-49, Plenum Press, New York (1985).
[2] Ning X., Ishida H.: Phenolic materials via ring-opening polymerization of benzoxazines: Effect of molecular structure on mechanical and dynamic mechanical properties. Journal of Polymer Science Part B: Polymer Physics, 32, 921-927 (1994). DOI: $10.1002 /$ polb.1994.090320515

[3] Ning X., Ishida H.: Phenolic materials via ring-opening polymerization: Synthesis and characterization of bisphenol-A based benzoxazines and their polymers. Journal of Polymer Science Part A: Polymer Chemistry, 32, 1121-1129 (1994). DOI: $10.1002 /$ pola.1994.080320614

[4] Ishida H., Rodriguez Y.: Catalyzing the curing reaction of a new benzoxazine-based phenolic resin. Journal of Applied Polymer Science, 58, 1751-1760 (1995). DOI: 10.1002 app.1995.070581013

[5] Ishida H., Rodriguez Y.: Curing kinetics of a new benzoxazine-based phenolic resin by differential scanning calorimetry. Polymer, 36, 3151-3458 (1995). DOI: $10.1016 / 0032-3861(95) 97878-J$

[6] Dungers J., Ishida H.: Vibrational assignments of N,Nbis(3,5-dimethyl-2-hydroxybenzyl)methylamine in the fingerprint region. Spectrochimica Acta Part A: Molecular and Biomolecular Spectroscopy, 51, 855867 (1995).

DOI: 10.1016/0584-8539(94)00187-G

[7] Dungers J., Ishida H.: Vibrational assignment of 3alkyl-3,4-dihydro-6-methyl-2H-1,3-benzoxazines in the fingerprint region. Spectrochimica Acta Part A: Molecular and Biomolecular Spectroscopy, 51, 10611074 (1995).

DOI: 10.1016/0584-8539(94)00114-Q

[8] Ishida H., Allen D. J.: Physical and mechanical characterization of near-zero shrinkage polybenzoxazines. Journal of Polymer Science Part B: Polymer Physics, 34, 1019-1030 (1996).

DOI: 10.1002/(SICI)1099-0488(19960430)34:6<1019 $\because$ AID-POLB1>3.0.CO;2-T

[9] Shen S. B., Ishida H.: Synthesis and characterization of polyfunctional naphthoxazines and related polymers. Journal of Applied Polymer Science, 61, 15951605 (1996).

DOI: 10.1002/(SICI)1097-4628(19960829)61:9<1595 $\because$ AID-APP19>3.0.CO;2-P

[10] Ishida H., Allen D. J.: Mechanical characterization of copolymers based on benzoxazine and epoxy. Polymer, 37, 4487-4495 (1996).

DOI: 10.1016/0032-3861(96)00303-5

[11] Shen S. B., Ishida H.: Development and characterization of high-performance polybenzoxazine composites. Polymer Composites, 17, 710-719 (1996). DOI: $10.1002 / p c .10663$

[12] Dunkers J., Zarate E. A., Ishida H.: Crystal structure and hydrogen-bonding characteristics of $N, N$-bis(3,5dimethyl-2-hydroxybenzyl)methylamine, a benzoxazine dimer. The Journal of Physical Chemistry B, 100, 13514-13520 (1996).

DOI: $10.1021 / . j p 961293 \mathrm{e}$ 
[13] Ishida H., Low H. Y.: A study on the volumetric expansion of benzoxazine-based phenolic resin. Macromolecules, 30, 1099-1106 (1997).

DOI: $10.1021 / \mathrm{ma} 960539 \mathrm{a}$

[14] Russel V. M., Koenig J. L., Low H. Y., Ishida H.: Study of the characterization and curing of a phenyl benzoxazine using ${ }^{15} \mathrm{~N}$ solid-state nuclear magnetic resonance spectroscopy. Journal of Applied Polymer Science, 70, 1401-1411 (1998).

DOI: $10.1002 /($ SICI) 1097-4628(19981114)70:7<1401 $:$ AID-APP15>3.0.CO;2-2

[15] Russel V. M., Koenig J. L., Low H. Y., Ishida H.: Study of the characterization and curing of benzoxazines using ${ }^{13} \mathrm{C}$ solid-state nuclear magnetic resonance. Journal of Applied Polymer Science, 70, 1413 1425 (1998).

DOI: $10.1002 /($ SICI) 1097-4628(19981114)70:7<1413 $\because$ AID-APP16>3.0.CO;2-0

[16] Kim H. J., Brunovska Z., Ishida H.: Dynamic mechanical analysis on highly thermally stable polybenzoxazines with an acetylene functional group. Journal of Applied Polymer Science, 73, 857-862 (1999). DOI: 10.1002/(SICI)1097-4628(19990808)73:6<857:: AID-APP1>3.0.CO;2-C

[17] Brunovska Z., Ishida H.: Thermal study on the copolymers of phthalonitrile and phenylnitrile-functional benzoxazines. Journal of Applied Polymer Science, 73, 2937-2949 (1999).

DOI: 10.1002/(SICI)1097-4628(19990929)73:14<2937 $\because$ AID-APP18>3.0.CO;2-E

[18] Shen S. B., Ishida H.: Dynamic mechanical and thermal characterization of high-performance polybenzoxazines. Journal of Polymer Science Part B: Polymer Physics, 37, 3257-3268 (1999).

DOI: $10.1002 /($ SICI)1099-0488(19991201)37:23<3257 :AID-POLB1>3.0.CO;2-0

[19] Rimdusit R., Ishida H.: Development of new class of electronic packaging materials based on ternary systems of benzoxazine, epoxy, and phenolic resins. Polymer, 41, 7941-7949 (2000). DOI: 10.1016/S0032-3861(00)00164-6

[20] Wang Y-X., Ishida H.: Development of low-viscosity benzoxazine resins and their polymers. Journal of Applied Polymer Science, 86, 2953-2966 (2002).

DOI: 10.1002/app.11190

[21] Kim H-D., Ishida H.: Model compounds study on the network structure of polybenzoxazines. Macromolecules, 36, 8320-8329 (2003).

DOI: $10.1021 / \mathrm{ma} 030108+$

[22] Chaisuwan T., Ishida H.: High-performance maleimide and nitrile-functionalized benzoxazines with good processibility for advanced composites applications. Journal of Applied Polymer Science, 101, 548-558 (2006).

DOI: 10.1002/app.23509
[23] Ishida H., Ohba S.: Thermal analysis and mechanical characterization of maleimide-functionalized benzoxazine/epoxy copolymers. Journal of Applied Polymer Science, 101, 1670-1677 (2006).

DOI: $10.1002 /$ app. 22499

[24] Allen D. J., Ishida H.: Physical and mechanical properties of flexible polybenzoxazine resins: Effect of aliphatic diamine chain length. Journal of Applied Polymer Science, 101, 2798-2809 (2006).

DOI: 10.1002/app.22501

[25] Jang J., Shin S.: Cure studies of a benzoxazine-based phenolic resin by isothermal experiment. Polymer Journal, 27, 601-606 (1995).

DOI: $10.1295 /$ polymj. 27.601

[26] Jang J., Seo D.: Performance improvement of rubbermodified polybenzoxazine. Journal of Applied Polymer Science, 67, 1-10 (1998).

DOI: $10.1002 /($ SICI) $1097-4628(19980103) 67: 1<1:$ : AID-APP1>3.0.CO;2-V

[27] Agag T., Takeichi T.: Preparation, characterization, and polymerization of maleimidobenzoxazine monomers as a novel class of thermosetting resins. Journal of Polymer Science Part A: Polymer Chemistry, 44, 1424-1435 (2006).

DOI: $10.1002 /$ pola.21245

[28] Liu Y-L., Yu J-M.: Cocuring behaviors of benzoxazine and maleimide derivatives and the thermal properties of the cured products. Journal of Polymer Science Part A: Polymer Chemistry, 44, 1890-1899 (2006). DOI: $10.1002 /$ pola.21290

[29] Liu Y-L., Chou C-I.: High performance benzoxazine monomers and polymers containing furan groups. Journal of Polymer Science Part A: Polymer Chemistry, 43, 5267-5282 (2005). DOI: $10.1002 /$ pola.21023

[30] Liu Y., Zheng S.: Inorganic-organic nanocomposites of polybenzoxazine with octa(propylglycidyl ether) polyhedral oligomeric silsesquioxane. Journal of Polymer Science Part A: Polymer Chemistry, 44, 11681181 (2006). DOI: $10.1002 /$ pola.21231

[31] Lee Y-J., Kuo S-W., Hung C-F., Chang F-C.: Synthesis and characterization of polybenzoxazine networks nanocomposites containing multifunctional polyhedral oligomeric silsesquioxane (POSS). Polymer, 47, 43784386 (2006).

DOI: 10.1016/j.polymer.2006.03.111

[32] Yei D-R., Fu H-K., Chen W-Y., Chang F-C.: Synthesis of a novel benzoxazine monomer-intercalated montmorillonite and the curing kinetics of polybenzoxazine/clay hybrid nanocomposites. Journal of Polymer Science Part B: Polymer Physics, 44, 347-358 (2006). DOI: $10.1002 /$ polb.20693 
[33] Chen Q., Xu R., Yu D.: Multiwalled carbon nanotube/polybenzoxazine nanocomposites: Preparation, characterization and properties. Polymer, 47, 77117719 (2006).

DOI: $10.1016 /$ j.polymer.2006.08.058

[34] Kimura H., Matsumoto A., Hasegawa K., Ohtsuka K., Fukuda A.: Epoxy resin cured by bisphenol A based benzoxazine. Journal of Applied Polymer Science, 68, 1903-1910 (1998).

DOI: $10.1002 /($ SICI)1097-4628(19980620)68:12<1903 $\because$ AID-APP2>3.0.CO;2-P

[35] Kimura H., Matsumoto A., Hasegawa K., Fukuda A.: New thermosetting resin from bisphenol A-based benzoxazine and bisoxazoline. Journal of Applied Polymer Science, 72, 1551-1558 (1998).

DOI: 10.1002/(SICI)1097-4628(19990620)72:12<1551 $\because$ AID-APP7>3.0.CO;2-5

[36] Kimura H., Murata Y., Matsumoto A., Hasegawa K., Ohtsuka K., Fukuda A.: New thermosetting resin from terpenediphenol-based benzoxazine and epoxy resin. Journal of Applied Polymer Science, 74, 2266-2273 (1999).

DOI: $10.1002 /($ SICI) 1097-4628(19991128)74:9<2266 $\because$ AID-APP16>3.0.CO;2-5

[37] Kimura H., Matsumoto A., Sugito H., Hasegawa K., Ohtsuka K., Fukuda A.: New thermosetting resin from poly( $p$-vinylphenol) based benzoxazine and epoxy resin. Journal of Applied Polymer Science, 79, 555565 (2001).

DOI: $10.1002 / 1097-4628(20010118) 79: 3<555:: A I D-$ APP190>3.0.CO;2-H

[38] Kimura H., Taguchi S., Matsumoto A.: Studies on new type of phenolic resin (IX) curing reaction of bisphenol A-based benzoxazine with bisoxazoline and the properties of the cured resin. II. Cure reactivity of benzoxazine. Journal of Applied Polymer Science, 79, 2331-2339 (2001).

DOI: 10.1002/1097-4628(20010328)79:13<2331::AIDAPP1041>3.0.CO;2-9
[39] Kimura H., Matsumoto A., Ohtsuka K.: New type of phenolic resin - The curing reaction of bisphenol A based benzoxazine with bisoxazoline and the properties of the cured resin. III. The cure reactivity of benzoxazine with a latent curing agent. Journal of Applied Polymer Science, 107, 710-718 (2008).

DOI: 10.1002 app.26963

[40] Kimura H., Matsumoto A., Ohtsuka K.: Studies on new type of phenolic resin - Curing reaction of bisphenol-A-based benzoxazine with epoxy resin using latent curing agent and the properties of the cured resin. Journal of Applied Polymer Science, 109, 1248-1256 (2008).

DOI: $10.1002 /$ app. 28279

[41] Kimura H., Matsumoto A., Ohtsuka K.: New type of phenolic resin: Curing reaction of phenol-novolac based benzoxazine with bisoxazoline or epoxy resin using latent curing agent and the properties of the cured resin. Journal of Applied Polymer Science, 112, 1762-1770 (2009).

DOI: 10.1002/app.29301

[42] Reghunadhan Nair C. P., Mathew D., Ninan K. N.: Cyanate ester resins, recent developments. in 'Advances in polymer science: New polymerization techniques and synthetic methodologies' (eds.: Abe A., Albertsson A-C., Cantow H-J., Dušek K., Edwards S., Höcker H., Joanny J. F., Kausch H-H., Kobayashi T., Lee K-S., McGrath J. E., Monnerie L., Stupp S. I., Suter U. W., Wegner G., Young R. J.) Springer, Berlin, Vol. 155, 199 (2001).

[43] Hamerton I.: Chemistry and technology of cyanate ester resins. Blackie Academic and Professional, New York (1994).

[44] Kwei K. T.: Viscoelasticity of crosslinked epoxy polymer in the transition region. Journal of Polymer Science Part A-2: Polymer Physics, 4, 943-949 (1966). DOI: $10.1002 /$ pol.1966.160040609 